\title{
CORPORATE TAX GAMES WITH CROSS-BORDER EXTERNALITIES FROM PUBLIC INFRASTRUCTURE
}

\author{
GERDA DEWIT, KATE HYNES and DERMOT LEAHY
}

\begin{abstract}
We construct a model of corporate tax competition in which governments also use public infrastructure investment to attract foreign direct investment, thus enhancing their tax bases. In doing so, we allow for cross-border infrastructural externalities. Depending on the externality, governments are shown to strategically over- or underinvest in infrastructure. We also examine how tax cooperation influences investment in infrastructure and find that welfare may be lower under tax cooperation than under tax competition; this is the case when infrastructure is very effective in raising the tax base and generates a large negative cross-border externality. (JEL F23, H40)
\end{abstract}

\section{INTRODUCTION}

As economic globalization deepens, countries tend to compete fiercely with each other to attract foreign direct investment (FDI), often using favorable tax rates. This is evident both from the often heated political debate on corporate taxes ${ }^{1}$ and has also been emphasized by the vast academic literature on tax competition. While the tax rate in the prospective host location matters for a firm's location decision, its actual location choice typically hinges on a combination of host location characteristics, among which infrastructure plays a prominent role (as shown by Brakman, Garretsen, and van Marrewijk 2002 and suggested in earlier theoretical work, e.g., Taylor 1992). ${ }^{2}$

Dewit: Lecturer, Department of Economics, Finance and Accounting, National University of Ireland Maynooth, Maynooth, Ireland. Phone 353-1-7083776, Fax 353-17083934, E-mail gerda.dewit@mu.ie

Hynes: Lecturer, School of Economics, University College Dublin, Dublin 4, Ireland. Phone 353-1-7168386, E-mail kate.hynes@ucd.ie

Leahy: Senior Lecturer, Department of Economics, Finance and Accounting, National University of Ireland Maynooth, Maynooth, Ireland. Phone 353-1-7083786, Fax 353-1-7083934, E-mail dermot.leahy@mu.ie

1. The debate on tax competition also often features in the press (e.g., "Heard that countries should compete on tax? Wrong," The Guardian, April 18, 2013).

2. Recent empirical work (e.g., Hauptmeier, Mittermaier, and Rincke 2012; Winner 2012) confirms that governments compete for mobile capital choosing a multidimensional policy package, consisting not only of a strategically chosen tax rate, but also of a strategically chosen level of productive public inputs.
In this article, we focus on the role of public infrastructure when there is tax competition. In doing so, we address two questions. First, we examine how governments' investment decisions in public infrastructure interact with their policy of corporate taxation. Second, as the possibility of tax harmonization has been on the political agenda for a long time now and seems even more pressing as globalization deepens, we explore how tax harmonization between two competing host countries affects those countries' investment in public infrastructure and their welfare.

Our article relates to three different strands in the literature. First and foremost, it fits in the literature that deals with competition for international firms. The bulk of this literature is concerned with tax competition. Following the theoretical work of Wilson (1986), empirical work provides strong evidence for tax competition between jurisdictions (e.g., Devereux, Lockwood, and Redoano 2008). ${ }^{3}$ Other work - albeit smaller in volume - has focused on infrastructural or public goods-related competition between jurisdictions to attract foreign firms and argues that this may lead to an overprovision of public goods. ${ }^{4}$ More

3. Recent surveys on tax competition include Zodrow (2010) and Baskaran and Lopes da Fonseca (2013).

4. Examples are Taylor (1992), Bayindir-Upmann (1998), Bucovetsky (2005), and Egger and Falkinger (2006).

\section{ABBREVIATIONS}

FDI: Foreign Direct Investment

LQ: Linear-Quadratic

OECD: Organisation for Economic Co-operation and Development 
recent work examines the link between tax rates and the provision of public goods when countries use both these policy instruments to compete for FDI. Notable examples of theoretical work are Zissimos and Wooders (2008), Hindriks, Peralta, and Weber (2008), Dembour and Wauthy (2009), and Pieretti and Zanaj (2011). ${ }^{5}$ Empirical work addressing the joint impact of tax rates and public inputs as determinants for attracting foreign firms is still small but growing. Bénassy-Quéré, Gobalraja, and Trannoy (2007) conclude that both the corporate tax rates and the public capital stock mattered for FDI by American firms into European countries. Görg, Molana, and Montagna (2009) use Organisation for Economic Co-operation and Development (OECD) data and find that high corporate tax rates do not necessarily dampen FDI if associated with the provision of public goods that improve the economic environment in which multinational firms operate. ${ }^{6}$ Recent empirical work provides direct evidence that governments are using public infrastructure together with corporate tax rates to attract mobile capital. This includes Gomes and Pouget (2008), who show that corporate tax rates and public investment are endogenous and also find evidence for international competition in both policy instruments. In a study that looks at German regions, Hauptmeier, Mittermaier, and Rincke (2012) focus on the strategic interaction between governments that not only choose corporate tax rates but also public inputs. They find that not only the strategic interaction effect between jurisdictions is significantly positive for tax rates, but also the direct interaction effect between jurisdictions is statistically different from zero for public input provision. In fact, it tends to be even larger than the direct interaction effect in taxes capital. These studies point to the deliberate use of both tax rates and public infrastructure provision to attract mobile capital.

Second, our model contributes to the literature on cross-border effects of public infrastructure. The nature of the externalities and in particular whether they are beneficial or harmful to neighboring countries or regions, depends both on the specific regions involved as well as on the

5. The setup in these papers is closest to the framework used in our article. There are, however, important differences between our article and these studies, which will be discussed when we elaborate on the specific contributions of our analysis.

6. See Chen et al. (2014) for an extension and updated version of this empirical study. type of public infrastructure. From a theoretical point of view, given two jurisdictions' relative attractiveness, infrastructure investment in one of the jurisdictions makes it more attractive to multinational firms and hence potentially has a "business-stealing" effect on the other region. Even if the investment in infrastructure in one region is not just local in that it connects its transport or telecommunications network to those in the other region, the latter does not necessarily benefit from that investment. Martin and Rogers (1995) distinguish between a country's investment in domestic and international infrastructure in a theoretical model without tax competition and emphasize the different effects of the two types of public infrastructure for firm location. Surveying the empirical evidence, Puga (2008) concludes that infrastructure investment projects generate externalities that may diffuse over wide geographical areas. Boarnet (1998) and Moreno and López-Bazo (2003) find evidence of public infrastructural investment having harmful effects on surrounding regions for Canada and Spain, respectively. By contrast, Cohen and Morrison Paul (2003) and Cohen and Morrison Paul (2003, 2004) present evidence of positive spatial spillovers of public infrastructure between U.S. states. ${ }^{7}$ Yu et al. (2012) present evidence for China, suggesting that public infrastructure spillovers are positive between some regions, negative between others, and zero for yet other regions. Naturally, cross-border externalities are also relevant across nations. Consider, for instance, how ports and airports in one country will affect other countries (see Dembour and Wauthy 2009). ${ }^{8}$ In short, the empirical literature offers evidence for negative and positive cross-border spillovers of public infrastructure investment.

Third, our work is also related to the literature on globalization and public spending. There is a growing literature that, contrary to conventional wisdom, globalization does not necessarily imply that public spending will fall. Rodrik (1998) provides empirical evidence for a positive relationship between the degree of openness of a country

7. More specifically, they found that hub airport expansion has a significant direct cost savings effect on own-state manufacturing production, and a roughly equal indirect cost effect on manufacturing industries in other states.

8. In a recent study aimed at determining cross-border spillovers from European gas infrastructure investment, Bouwmeester and Scholtens (2017) found that there were significant positive cross-border spillovers when countries invest in gas transmission infrastructure. 
and the size of its government. ${ }^{9}$ Our paper shows that the footlooseness of multinational firms does not necessarily imply a low level of public infrastructure investment. ${ }^{10}$ If governments invest in public infrastructure to attract mobile capital, this could result in an overprovision of those types of infrastructure that are of most interest to mobile firms with possible ramifications for public spending geared toward immobile residents. This potential side effect of using public infrastructure to attract mobile capital was predicted in the theoretical literature by Keen and Marchand (1997). In their words, "Crudely put, the picture that emerges is thus one in which fiscal competition leads to too many business centres and airports but not enough parks and libraries." 11 More recently, Winner (2012) finds evidence for just such a bias in the composition of public spending. Specifically, he examines whether infrastructural competition affects the composition of public spending, using data from 18 OECD economies (from 1980 to 2000). $\mathrm{He}$ provides support for the hypothesis that infrastructural competition will affect the composition of public spending and cause a shift from residential public goods to industrial public inputs, where the former benefit immobile residents and the latter benefit mobile production factors.

In this article, we characterize government strategies to attract footloose capital, taking into account the interdependence between corporate taxes and public infrastructure investment. Our model considers two jurisdictions, which compete for foreign firms in a two-stage game: they commit to public infrastructure levels in stage 1 - which captures the long-term nature of this investment decision - and compete for FDI with corporate taxes in stage 2 .

Our analysis is different in various respects from previous works and contributes to the aforementioned literature in several ways. First, unlike the setup in these papers, our framework allows for positive and negative cross-border spillovers from public infrastructure. ${ }^{12}$

9. Consistent with this observation, Alesina and Wacziarg (1998) show that smaller countries that are more open to trade also have a larger share of public consumption in gross domestic product.

10. This resonates with the findings on the relationship between corporate tax rates and the provision of public goods in Görg, Molana, and Montagna (2009).

11. Other theoretical work confirmed this prediction (see Cremer et al. 1997 for an overview).

12. Zissimos and Wooders (2008), Hindriks, Peralta, and Weber (2008), and Pieretti and Zanaj (2011) examine
Second, our model captures the fact that the game that countries play is rarely a zero-sum one: competing for business with lower taxes or higher infrastructure can be expected to lead to an increase in the total pool of FDI and to enhance the combined tax base of the competing countries. ${ }^{13}$ This modeling innovation is likely to be relevant for future empirical work that aims to measure the success of policy packages designed to attract FDI. Also important in this respect is that our work generalizes the model beyond specific functional forms.

Third, we examine a form of tax harmonization that should not just eliminate the harmful race-to-the-bottom in tax rates but allows similar countries to set their taxes to maximize joint welfare. Previous work has not examined actual tax cooperation. ${ }^{14}$ We show that, even when tax rates are cooperatively set by countries that are symmetric, welfare with tax harmonization may fall below welfare with tax competition.

Section II presents the building blocks of our framework. In Section III, we solve a simple model that captures the essence of our results. In Section IV, we move beyond the specific functional forms used in Section III to generalize our results and formalize them in propositions. In Section V, we discuss the welfare effects of tax harmonization when countries are symmetric. Section VI considers a number of extensions of our model such as asymmetric countries, an alternative move order, more than two jurisdictions, and a discussion of the effect of minimum tax rates as an alternative form of tax harmonization. Section VII presents the conclusion.

\section{THE MODEL SETUP}

Consider two jurisdictions, "Home" and "Foreign" (denoted by $\mathrm{H}$ and $\mathrm{F}$, respectively), which are both prospective host locations for multinational firms from other countries. The jurisdictions can be different countries or different

extremely negative externalities only, while Dembour and Wauthy (2009) only look at positive spatial spillovers.

13. Previous models of competition for firms typically model that competition using a Hotelling type setup, implying that the pool of possible foreign direct investment is fixed and the game prospective host countries play is a zero-sum game.

14. While some papers consider tax harmonization in the sense of a minimum tax rate or split-the-difference tax rate (Zissimos and Wooders 2008), others examine fiscal equalization schemes (Hindriks, Peralta, and Weber 2008) or cooperation in infrastructure (Dembour and Wauthy 2009). 
regions of the same country with independent tax raising authority as well as public infrastructure decision making power, but throughout the model we will refer to these jurisdictions as "countries." The two countries compete for third-country FDI as this generates benefits for each. One obvious benefit is the tax revenue that the government collects from multinationals. Naturally, these tax revenues increase in the actual amount of FDI attracted into the country. One way to increase the amount of FDI a country attracts is to lower its corporate tax rate, which in turn will raise the country's tax base. An increase in public infrastructure investment also increases the amount of FDI a country attracts, and, in addition, it raises the profits of the multinational plants that had already decided to locate in the country involved. Both effects of public infrastructure work toward increasing the country's tax base.

Tax revenues from multinationals located in $\mathrm{H}$ are represented by $t B$, where $t \in[0,1]$ is H's profit tax rate and $B$ denotes the aggregate pretax profits of multinational firms located in $\mathrm{H}$. For brevity, we will refer to $B$ as H's (multinational) tax base and $B^{*}$ as F's (multinational) tax base. These mobile tax base functions can be written as:

$$
B=B\left(t, t^{*}, x, x^{*}\right),
$$

and

$$
B^{*}=B^{*}\left(t, t^{*}, x, x^{*}\right) .
$$

We assume $B=0$ at $t=1$ and $B^{*}=0$ if $t^{*}=1$. Also, we assume $B_{t}<0$, where subscripts here and elsewhere denote partial derivatives. This captures the idea that a higher tax rate reduces the tax base as it reduces the inward FDI into $\mathrm{H}$. We have $B_{t^{*}}>0$ because the countries are substitute locations for multinational investment. The partial derivatives of $B^{*}$ are analogous. Local infrastructure can be expected to both make a location more attractive for multinational investment and to raise the profitability at that location. Since both of these effects work toward raising the aggregate pretax profits of multinationals in the region that invests in public infrastructure, $B_{x}>0$ and $B_{x^{*}}^{*}>0$. Signing the cross effects, $B_{x^{*}}$ and $B_{x}^{*}$, is less straightforward as these depend on whether the externality that one country's public infrastructure investment generates for the other is negative or positive. A rival host country's investment in public infrastructure may reduce a country's relative attractiveness to multinationals and therefore its multinational tax base. This could, for instance, be the case when the rival host location invests in education. However, some types of public infrastructure investment could be beneficial to countries other than the investing country itself. For example, a country's investment in a major local port may increase the attractiveness of other nearby prospective host countries as well. In that case, the investment in public infrastructure by one country entails a positive cross-border externality to the nearby country. We define the ratios $\lambda\left(t, t^{*}, x, x^{*}\right) \equiv B_{x}^{*} / B_{x}$ and $\lambda^{*}\left(t, t^{*}, x, x^{*}\right) \equiv B_{x^{*}} / B_{x^{*}}^{*} ; \lambda>0$ implies that the externality is positive $\left(B_{x}^{*}>0\right)$, while $\lambda<0$ indicates the externality is negative $\left(B_{x}^{*}<0\right) .{ }^{15} \mathrm{We}$ assume $-1 \leq \lambda \leq 1$ and $-1 \leq \lambda^{*} \leq 1$, which implies that the effect of a country's infrastructural investment is always at least as strong on the own country as its effect-whether positive or negative - on the competing country.

Welfare for $\mathrm{H}$ and $\mathrm{F}$, respectively, is given by:

$$
W\left(t, t^{*}, x, x^{*}\right)=t B\left(t, t^{*}, x, x^{*}\right)-\Omega(x)
$$

and

(2b)

$$
W^{*}\left(t, t^{*}, x, x^{*}\right)=t^{*} B^{*}\left(t, t^{*}, x, x^{*}\right)-\Omega^{*}\left(x^{*}\right)
$$

where $\Omega(x)$ and $\Omega^{*}\left(x^{*}\right)$ stand for the costs of infrastructural investment in $\mathrm{H}$ and $\mathrm{F}$, respectively. We assume that these are increasing convex functions of public infrastructure $\left(\Omega^{\prime \prime}(x)>0\right.$ and $\left.\Omega^{* \prime \prime}\left(x^{*}\right)>0\right)$.

In addition to improving the local business environment for inward FDI, public infrastructure clearly has many direct social and economic benefits. Furthermore, FDI, apart from generating tax revenue, can also provide many other benefits, and in some cases costs, to a country. For instance, it can affect the activity of domestic firms. We do not include taxes from domestic firms in $t B$, because, although they contribute to the general tax base, they do not contribute to the multinational tax base. ${ }^{16}$ However, there might be other good reasons to include the activity of

15. Naturally, it is possible that $B_{x^{*}} \leq 0$ while $B_{x}^{*} \geq 0$ and vice versa.

16. The tax revenue from domestic firms comes from domestic profits and earnings and represents a transfer between agents within the country. By contrast, tax revenue from multinational firms (captured by $t B$ ) is rent extracted from foreigners and is a net addition to welfare. Thus, it is important to disentangle the two. 
domestic firms in the welfare function. ${ }^{17}$ The effect of FDI on domestic firms could vary in sign depending on whether foreign firms benefit or hurt domestic firm activity. Thus, an increase in FDI could stimulate some domestic firms (for instance, inward FDI may generate technological spillovers to some domestic firms), while crowding out others. ${ }^{18}$ Furthermore, there may be beneficial interaction effects between public infrastructure and FDI; for instance, a more developed public infrastructure may allow a country to benefit to a greater extent from any spillovers from inward FDI. ${ }^{19}$

To take account of the effects on domestic business activity and other social effects, we will introduce an "additional benefit function" that captures all of the economic and social effects of public infrastructure and FDI that are not included in the revenue from the taxation of multinationals $\left(t B\right.$ and $\left.t^{*} B^{*}\right)$. We will represent these additional benefits to Home and Foreign by $g$ and $g^{*}$, respectively, and assume that $g(x$, $t, k)$ is increasing in Home infrastructure, $x$, and decreasing in $t$ as higher taxes would reduce domestic firm activity. Inward FDI, denoted by $k$, could have overall positive or negative effects on $g$ as discussed above. Inward FDI is decreasing in $t$ and increasing in $t^{*}$ and $x$. The volume of FDI may also depend on $x^{*}$, though the sign is ambiguous. Taking all these effects into account, we can write the nontax benefits of inward FDI and public infrastructure in compact form as $G\left(t, t^{*}, x, x^{*}\right)=g\left[k\left(t, t^{*}, x, x^{*}\right), x, t\right]$ and $G^{*}\left(t, t^{*}, x, x^{*}\right)=g^{*}\left[k\left(t, t^{*}, x, x^{*}\right), x^{*}, t^{*}\right]$ for Home and Foreign, respectively. Including these benefits into expressions (2a) and (2b) gives us the enhanced welfare functions for the respective countries. The sign of the partial derivatives of $G\left(t, t^{*}, x, x^{*}\right)$ will be affected by that of $g_{k}$. In the case in which this is positive, implying that an increase in FDI has positive additional benefits on the domestic country, we get $G_{t}<0, G_{t^{*}}>0, G_{x}>0$, and $G_{x^{*}}$ ambiguous. If $g_{k}$ is negative, due perhaps to the crowding

17. For instance, the government may be concerned with the employment they provide or their contribution to export earnings. Thus, the activity of domestic firms could enter the welfare function directly. We would expect the direct effect of the tax on domestic firms to be negative, while the direct effect of local public infrastructure would be positive for domestic firms.

18. On possible crowding out effects of FDI, see, for instance, Aitkin and Harrison (1999) and Jude (2015).

19. A report by the OECD () points to the importance of policies that maximize the benefits from FDI, especially for newly emerging and developing economies. out of domestic firms, then some of these signs could be reversed (we will return to this in subsection IV.A). The partial derivatives of $G^{*}\left(t, t^{*}, x, x^{*}\right)$ are analogous. Throughout our analysis, we will use the welfare functions in expressions (2a) and (2b), but will point out briefly when and how our qualitative results would change if the enhanced welfare expressions were used.

We will consider two two-stage games. In one game, jurisdictions choose taxes noncooperatively; in the other, they set tax rates cooperatively. In the first stage of each game, governments simultaneously choose investment levels in public infrastructure and subsequently, in the second stage, they set corporate tax rates. We solve each game by backward induction. The move order is based on the fact that infrastructure investment typically has more commitment value than taxes as it involves a long-run decision and is to a large extent irreversible. ${ }^{20}$

We first solve a specific case of our model, in which we use a linear function for each region's multinational tax base and a quadratic function for the regional cost of public infrastructure investment. The use of these special functional forms allows us to side step the technicalities involved in solving the general model and thus present our results in as transparent a way as possible. We will refer to this case as the "linear-quadratic" (LQ) case. Subsequently, we generalize the model and formulate our results in propositions.

\section{THE LINEAR-QUADRATIC CASE}

In the LQ case, the multinational tax bases in $\mathrm{H}$ and $\mathrm{F}$ are, respectively, given by:

$$
B=\alpha-\beta\left(t-\epsilon t^{*}\right)+\gamma\left(x+\lambda x^{*}\right)
$$

and

20. We have followed the standard practice in assuming that infrastructure is chosen before the taxes (see among other Zissimos and Wooders 2008 and Pieretti and Zanaj 2011). The reason for the widespread preference for this assumption about the move order is that public infrastructure, which takes time to build, is seen as more difficult to change than taxes. In another part of the multistage game theory literature this is the reason why in capacity and price games firms are modeled as choosing capacity first and then price (e.g., the very influential paper by Kreps and Scheinkman 1983). In their model, price is seen as easier to change than capacity. So we assume that governments set infrastructure first as this variable has more commitment value than the corporate tax rate because of its innate irreversibility. 


$$
B^{*}=\alpha-\beta\left(t^{*}-\epsilon t\right)+\gamma\left(x^{*}+\lambda x\right) .
$$

In expressions (3a) and (3b), $\alpha, \beta$, and $\gamma$ are positive, $0<\epsilon<1$ and $-1 \leq \lambda \leq 1$, so that the sign of the partial derivatives of $B$ and $B^{*}$ are as discussed in the previous section. ${ }^{21}$ The respective public infrastructure investment cost functions for $\mathrm{H}$ and $\mathrm{F}$ are, respectively, given by $\Omega(x)=(\omega / 2) x^{2}$ and $\Omega^{*}\left(x^{*}\right)=(\omega / 2) x^{* 2}$, with $\omega>0$. As indicated by our expressions, we assume for now that the two countries are completely symmetric. We examine the effect of asymmetry between the countries in Section VI.

\section{A. Tax Competition}

First consider the game in which taxes are set noncooperatively.

Stage 2: Noncooperative Tax Setting. The governments simultaneously and noncooperatively choose taxes given infrastructural investment levels $x$ and $x^{*}$. The Home government maximizes Home welfare with respect to $t$, which yields its tax reaction function, $t=\psi\left(t^{*} ; x, x^{*}\right)$ :

$$
\begin{aligned}
t=\psi\left(t^{*} ; x, x^{*}\right) & =\left(\alpha+\gamma\left(x+\lambda x^{*}\right)\right) / 2 \beta \\
& +(\epsilon / 2) t^{*}
\end{aligned}
$$

The tax reaction function for the Foreign government is analogous. From expression (4), we can see that taxes are strategic complements. The tax reaction functions shift outward in the country's own public infrastructure investment and in the competing country's public infrastructure investment if the latter generates a positive externality. $t^{N}$, is:

The equilibrium tax rate for Home, denoted by<smiles>[AsH2]</smiles>

$$
\begin{aligned}
t^{N}= & {[(2+\epsilon) \alpha] /\left[\beta\left(4-\epsilon^{2}\right)\right] } \\
& +\gamma\left[(2+\epsilon \lambda) x+(2 \lambda+\epsilon) x^{*}\right] /\left[\beta\left(4-\epsilon^{2}\right)\right] .
\end{aligned}
$$

21. These functional forms allow us to move beyond the Hotelling case, used in earlier work. The standard Hoteling case implies a fixed pool of FDI. By contrast, in our setup multinational firms - as indeed they do in the real world-have an outside option such as producing in other locations and serving a market from a distance by exporting. What is more, the Hotelling model restricts $\lambda$ to -1 , which implies a complete and negative cross-border spillover. By contrast, the functional forms used here allow us to examine different types and levels of the externality and assess how beneficial cooperation is in those different scenarios. This is useful, given that, empirically, the externality seems to depend on the type of infrastructure and features of the jurisdictions.
Given symmetry, the equilibrium tax rate in Foreign, $t^{* N}$, takes the same form with the role of $x$ and $x^{*}$ reversed.

Let us now examine how investment in public infrastructure affects equilibrium tax rates. A country's tax rate is always increasing in its own investment in public infrastructure $\left(\mathrm{d} t^{N} / \mathrm{d} x>0\right.$ from expression (5)). The effect of a country's investment in public infrastructure on the other host country's corporate tax rate $\left(\mathrm{d} t^{N} / \mathrm{d} x^{*}\right)$ is ambiguous and depends on the externality on the rival host country. When a country's infrastructure investment generates a positive or not too negative externality for the rival host country (i.e., $\lambda>\bar{\lambda} \equiv-\epsilon / 2$ ), it raises the latter's tax rate, but the opposite is true when the externality is negative and sufficiently strong (i.e., $\lambda<\bar{\lambda} \equiv-\epsilon / 2)$.

Stage 1: Investment in Public Infrastructure under Tax Competition. We now determine each country's optimal investment level in infrastructure. For ease of exposition, we focus on H's choice. F's choice of investment is completely analogous. Home maximizes welfare with respect to $x$, taking $t^{N}=t^{N}\left(x, x^{*}\right)$ (see expression (5)) and $t^{* N}=t^{* N}\left(x, x^{*}\right)$ into account. This yields the first-order condition for $x$ :

$$
\begin{aligned}
\mathrm{d} W / \mathrm{d} x & =W_{x}+W_{t}\left(\mathrm{~d} t^{N} / \mathrm{d} x\right) \\
& +W_{t^{*}}\left(\mathrm{~d} t^{* N} / \mathrm{d} x\right)=0 .
\end{aligned}
$$

Using the envelope theorem, $W_{t}=0$ from the second stage. When discussing expression (6), it proves helpful to use the "strategic investment" terminology pioneered by Fudenberg and Tirole (1984). The first term in expression (6) is the direct effect of $x$ on Home welfare, with $W_{x}=t \gamma-\omega x$. Let us focus on this term first. If governments were to choose public infrastructure investment simultaneously to setting taxes, $\mathrm{H}$ would choose $x$ such that $W_{x}=0$, implying that the marginal direct benefits of public infrastructure investment would be equal to its marginal costs (i.e., $t \gamma=\omega x$ ). We will henceforth refer to this hypothetical case, in which $W_{x}=0$, as the "nonstrategic simultaneous-move benchmark." The last term in expression (6) is the "strategic" term $\left(W_{t^{*}}\left(\mathrm{~d} t^{* N} / \mathrm{d} x\right)\right)$. The sign of this term determines whether the Home government will-in the terminology of Fudenberg and Tirole (1984) — "over-" or "under" invest, relative to the hypothetical nonstrategic benchmark, in order to manipulate the tax rates set in the 
rival jurisdiction. If the strategic term is positive, then the first term in expression (6) has to be negative $\left(W_{x}<0\right)$ and we say that the Home government "over" invests in public infrastructure relative to the nonstrategic benchmark. It is important to stress that by overinvestment, we certainly do not mean unproductive investment. In our model, all the infrastructural investment is productive in raising the multinational tax base. Investment in infrastructure raises the tax base directly; in some circumstances it raises the other jurisdiction's optimal tax rate. When it does, the marginal benefit of infrastructural investment is increased and the optimal level is higher than it would be in the nonstrategic simultaneous-move benchmark. If the strategic term is negative, then the opposite holds $\left(W_{x}>0\right)$ and the government "under" invests relative to the nonstrategic benchmark.

To determine which of these cases will occur, we need to examine the strategic term in detail. The term can be decomposed into $W_{t^{*}}$ and $\mathrm{d} t^{* N} / \mathrm{d} x$. We have $W_{t^{*}}=t \beta \epsilon>0$, implying that the Foreign tax rate is "friendly," which means that a rise in Foreign's tax rate increases Home welfare. $^{22}$ The sign of the strategic term therefore depends on the sign of $\mathrm{d} t^{* N} / \mathrm{d} x$, which, as shown earlier, depends on the sign of $2 \lambda+\epsilon$. So, if $\lambda$ is above the threshold $\bar{\lambda}=-\epsilon / 2$ (hence, $\left.\mathrm{d} t^{* N} / \mathrm{d} x>0\right)$, then Home will "over" invest in public infrastructure $\left(W_{t^{*}}\left(\mathrm{~d} t^{* N} / \mathrm{d} x\right)>0\right.$, hence $\left.W_{x}<0\right)$. However, when $\lambda<\bar{\lambda}=-\epsilon / 2$, it will "under" invest $\left(W_{t^{*}}\left(\mathrm{~d} t^{* N} / \mathrm{d} x\right)<0\right.$, hence $\left.W_{x}>0\right)$.

Intuitively, governments wish to avoid a race to the bottom in corporate tax rates and will act strategically when choosing their investment levels in public infrastructure. When a country's investment in public infrastructure raises the rival host country's tax rate, it will choose to increase its investment, as a high tax rate in the rival host country will allow the investing country to set a high tax rate itself. When its investment does the opposite, the investing country will avoid low tax rates by limiting its investment in public infrastructure.

The equilibrium level of public infrastructure investment in $\mathrm{H}$ is:

$$
x^{N}=[2 \eta \alpha(2+\epsilon \lambda)] / D^{N}
$$

22. Brander (1995) was the first to refer to this type of cross derivative as the "friendliness" term. with $D^{N} \equiv \gamma\left[\beta(2-\epsilon)\left(4-\epsilon^{2}\right)-2 \eta(1+\lambda)(2+\epsilon \lambda)\right]$ $>0$, where $\eta \equiv \gamma^{2} / \omega$ is a measure of the relative effectiveness of public infrastructure investment.

\section{B. Tax Cooperation}

Here, we continue to assume that countries choosing their public infrastructure investment levels, $x$ and $x^{*}$, in stage 1, do so independently. However, the tax rate, set in stage 2, is now common. We will assume that the governments can set the harmonized tax at the jointly optimal level given the infrastructure levels set in stage 1 . We have chosen to model tax harmonization as tax cooperation as it would be expected to be more favorable than any other forms of tax harmonization. Our analysis thus provides us with a first rule of thumb for assessing the success of tax harmonization initiatives: if the conditions are such that even actual tax cooperation reduces welfare of the countries involved, the prospects for finding a simple welfare improving form of tax harmonization would seem very remote. ${ }^{23}$

Using expression (3a) and setting $t=t^{*}=\tau$, the expression for the multinational tax base in Home is now given by:

$$
B=\alpha-\beta(1-\epsilon) \tau+\gamma\left(x+\lambda x^{*}\right) .
$$

The common tax rate is chosen to maximize the sum of Home and Foreign welfare, $W+W^{*}$, taking account of the fact that, at this stage, public infrastructure has already been chosen. The firstorder condition for the jointly optimal tax rate is:

$$
W_{\tau}+W_{\tau}^{*}=\tau\left(B_{\tau}+B_{\tau}^{*}\right)+B+B^{*}=0,
$$

implying that the common tax rate under tax cooperation is given by:

$$
\tau^{C}=\frac{2 \alpha+\gamma(1+\lambda)\left(x+x^{*}\right)}{4 \beta(1-\epsilon)} .
$$

Investment in public infrastructure in either country (weakly) raises the common tax rate $\left(d \tau^{C} / d x=d \tau^{C} / d x^{*}=\gamma(1+\lambda) /[4 \beta(1-\epsilon)] \geq 0\right)^{24}$.

In stage 1 , Home and Foreign choose their public infrastructure investment levels noncooperatively, taking account of the effect on the

23. We discuss another form of tax harmonization in Section VI.

24. We assume $\epsilon<1$ to ensure an interior cooperative optimum. This captures the stylized fact that as the cooperative tax rises it negatively influences the tax base. Note that in the standard Hotelling case, $\epsilon=1$ and the cooperative (joint optimal) tax would be confiscatory. 
future cooperatively set corporate tax. The firstorder condition for Home welfare maximization with respect to infrastructural investment is:

$$
W_{x}+W_{\tau}\left(\mathrm{d} \tau^{C} / \mathrm{d} x\right)=0
$$

with $W_{x}=\gamma \tau-\omega x$ and $W_{\tau}=B-\beta(1-\epsilon) \tau$. The first-order condition for Foreign welfare maximization is similar. As $\mathrm{d} \tau^{C} / \mathrm{d} x=\mathrm{d} \tau^{C} / \mathrm{d} x^{*}>0$, the sign of the strategic term in expression (11) depends on the friendliness term, $W_{\tau}$. As expression (9) can, given symmetry, be rewritten as $W_{\tau}+W_{\tau}^{*}=2 W_{\tau}=0$, it implies $W_{\tau}=0$. This means that the strategic term in expressions (11) vanishes and hence neither country invests strategically. As expression (11) reduces to $W_{x}=0$ and with $\tau^{C}$ given by expression (10), optimal public infrastructure investment levels under tax cooperation (denoted by $x^{C}$ and $x^{*}$ ), are then given by:

$$
x^{C}=x^{* C}=\eta \alpha / D^{C}
$$

with $D^{C}=\gamma[2 \beta(1-\epsilon)-\eta(1+\lambda)]>0$ to guarantee stability.

In Figure 1 we depict the first-order conditions for infrastructure and taxes in symmetric $(x, t)$ space; these are drawn for tax competition $\left(x^{N}(t)\right.$ and $\left.t^{N}(x)\right)$ and for tax cooperation $\left(x^{C}(\tau)\right.$ and $\tau^{C}(x)$ ). In both Figures $1 \mathrm{~A}$ and $\mathrm{B}$, the equilibrium under tax competition is indicated by point $\mathrm{N}$ and the equilibrium under tax cooperation by point $\mathrm{C}$. Figure 1A illustrates the two equilibria for $\lambda>\bar{\lambda}$, while Figure $1 \mathrm{~B}$ does so when $\lambda<\bar{\lambda}$.

Before discussing the welfare effects of tax cooperation, we will generalize the model in the next section and formulate our results in propositions.

\section{THE GENERAL MODEL}

In this section, we generalize our results obtained for the LQ case. For this purpose, we use the general function forms specified in Section II and unless otherwise stated we do not impose symmetry. The purpose of this section is to explore the robustness of our model. With linear functional forms taxes are strategic complements and the threshold level of externality below which countries strategically underinvest in infrastructure to reduce the rival's taxes is negative. We extend the analysis by allowing for the possibility that taxes could be strategic substitutes rather than complements and study how this affects the critical threshold. We show that the sign of the threshold depends on whether taxes are strategic substitutes or complements.

\section{A. Tax Competition}

Again, we first consider the game in which taxes are set noncooperatively.

Stage 2: Noncooperative Tax Setting. In stage 2 , governments simultaneously and noncooperatively choose taxes, given infrastructural investment levels $x$ and $x^{*}$, to maximize expressions (2a) and (2b). First-order conditions associated with welfare maximization, $W_{t}\left(t, t^{*}, x, x^{*}\right)=0$ for $\mathrm{H}$ and $W_{t^{*}}^{*}\left(t^{*}, t, x^{*}, x\right)=0$ for $\mathrm{F}$, yield H's and F's tax reaction functions, given by $t=\psi\left(t^{*} ; x, x^{*}\right)$ and $t^{*}=\psi^{*}\left(t ; x, x^{*}\right)$, respectively.

Let us now examine the properties of these reaction functions. The slope of H's tax best response functions is given by $\psi_{t^{*}}=-W_{t t^{*}} / W_{t t}$. As the second-order conditions require $W_{t t}<0$, the sign of $\psi_{t^{*}}$ is the same as that of $W_{t t^{*}}$, with $W_{t t^{*}}=B_{t^{*}}+t B_{t t^{*}}$. The term $B_{t^{*}}$ is positive and so works toward $W_{t t^{*}}$ and $\psi_{t^{*}}$ being positive. The intuition is that an increase in the tax in $\mathrm{F}$ makes $\mathrm{H}$ a relatively attractive location and, since this increases Home's tax base, it works toward raising the marginal benefit of the tax. The sign of $t B_{t t^{*}}$ is ambiguous. However, provided that this term is not too negative, the tax best-response functions are positively sloped and corporate tax rates are strategic complements. One can think of this as the "normal case," which is guaranteed in the LQ case but not in general. The following assumption ensures that the cross effects, $W_{t t^{*}}$ and $W_{t^{*} t}^{*}$, do not dominate the direct effects, $W_{t t}$ and $W_{t^{*} t^{*}}^{*}$, and guarantees the stability of the tax game:

ASSUMPTION 1. $\left|W_{t t}\right|>\left|W_{t t^{*}}\right|$ and $\left|W_{t^{*} t^{*}}^{*}\right|>\left|W_{t^{*} t}^{*}\right|$.

We now examine the impact of investment in public infrastructure on the reaction functions. Investment in public infrastructure causes them to shift. The impact on H's reaction function is captured by $\psi_{x}=-W_{t x} / W_{t t}$ and, similarly, by $\psi_{x^{*}}=$ $-W_{t x^{*}} / W_{t t}$. As we have $W_{t}=B+t B_{t}=0$, and hence $t=-B / B_{t}$, we can rewrite $W_{t x}=B_{x}+t B_{t x}$ as $W_{t x}=B_{x}-B_{t x}\left(B / B_{t}\right)$. Similarly, we can rewrite $W_{t x^{*}}=B_{x^{*}}+t B_{t x^{*}}$ as $B_{x^{*}}-B_{t x^{*}}\left(B / B_{t}\right)$. Defining $R \equiv 1-\left(B / B_{t}\right)\left(B_{t x} / B_{x}\right)$ and $r \equiv$ $1-\left(B / B_{t}\right)\left(B_{t x^{*}} / B_{x^{*}}\right)$, we can write $W_{t x}=R B_{x}$ and $W_{t x^{*}}=r B_{x^{*}}$. Let $R^{*}$ and $r^{*}$ be analogously 


\section{FIGURE 1}

First-Order Conditions under Tax Competition and Tax Cooperation-The Symmetric Linear-Quadratic Case. (A) $\lambda>\bar{\lambda}$, (B) $\lambda<\bar{\lambda}$

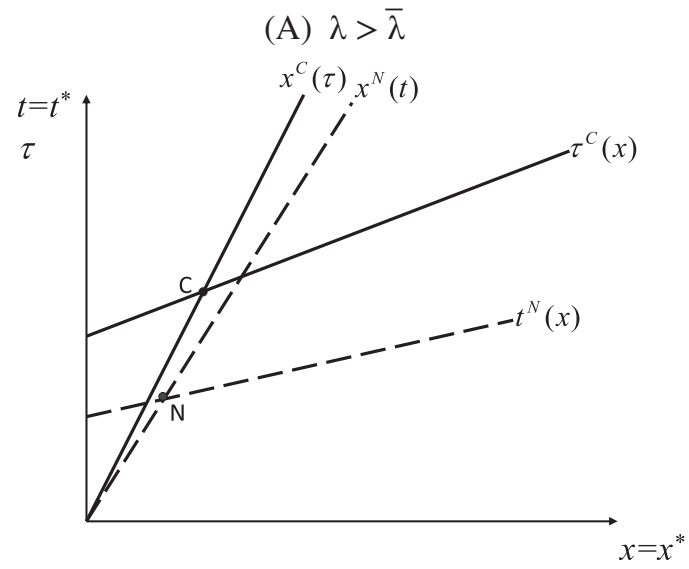

defined for the Foreign jurisdiction. We will assume that the following reasonable restriction holds:

ASSUMPTION 2. $R>0, \quad r>0, \quad R^{*}>0 \quad$ and $r^{*}>0$.

This condition is guaranteed to hold in many special cases including the LQ case discussed in the previous section. $R>0$ implies that the tax elasticity of the region's multinational tax base $\left(-B_{t}(t / B)\right)$ is decreasing in public infrastructure investment. ${ }^{25}$ The idea here is that inflows of FDI become less sensitive to corporate taxes when the region is more attractive because of higher infrastructural provision. Likewise, $r>0$ implies that, if F's investment makes H's location less attractive on infrastructural grounds, then H's multinational tax base becomes more sensitive to taxes. ${ }^{26}$ From Assumption 2, $\psi_{x}>0$. The sign of $\psi_{x^{*}}$, which captures the cross effect of Foreign's public infrastructure on Home's tax reaction function, depends on that of $B_{x^{*}}$ and is therefore ambiguous. We assume that the absolute impact of own investment on the own tax reaction function is at least as large as its impact on the rival reaction function, or:

25. That is, $-\partial\left(B_{t} t / B\right) / \partial x=t B_{t} B_{x} R / B^{2}<0$. This implies $R>0$ as $B_{t}<0$ and $B_{x}>0$.

26. Or, $r>0$ implies the elasticity of H's multinational tax base does not decrease if F's investment tends to reduce the gross pretax profits in $\mathrm{H}$.
(B) $\lambda<\bar{\lambda}$

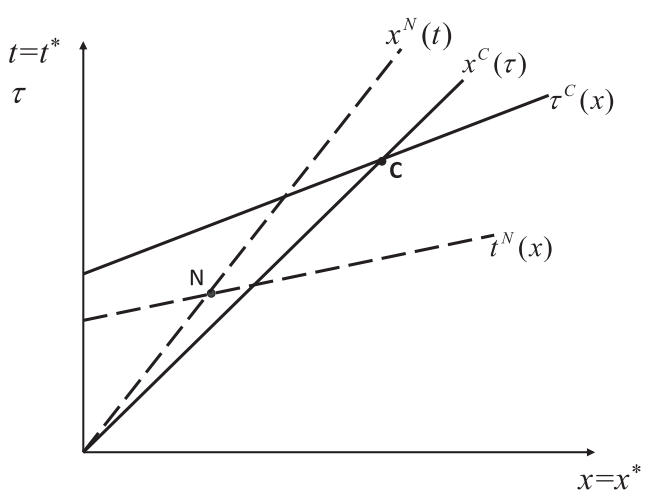

ASSUMPTION 3. $\left|\psi_{x}\right| \geq\left|\psi_{x}^{*}\right|$ and $\left|\psi_{x^{*}}^{*}\right| \geq$ $\left|\psi_{x^{*}}\right|$.

Note that all of the above Assumptions hold automatically in the LQ version of the model.

Equilibrium tax rates-obtained by solving the reaction functions-depend on the levels of public infrastructure governments invested in period one and can be written as $t^{N}=t^{N}\left(x, x^{*}\right)$ and $t^{* N}=t^{* N}\left(x, x^{*}\right)$. We restrict attention to unique equilibria:

ASSUMPTION 4. For given infrastructural investment levels, the tax equilibrium $\left\{t^{N}\left(x, x^{*}\right)\right.$, $\left.t^{* N}\left(x, x^{*}\right)\right\}$ is unique.

To determine the effect of $x$ on equilibrium tax rates, we totally differentiate the first-order conditions for welfare maximization and obtain:

$$
\frac{\mathrm{d} t^{N}}{\mathrm{~d} x}=\frac{W_{t^{*} x}^{*} W_{t t^{*}}-W_{t^{*} t^{*}}^{*} W_{t x}}{\Delta}
$$

and

$$
\frac{\mathrm{d} t^{* N}}{\mathrm{~d} x}=\frac{W_{t x} W_{t^{*} t}^{*}-W_{t t} W_{t^{*} x}^{*}}{\Delta}
$$

with $\Delta \equiv W_{t t} W_{t^{*} t^{*}}^{*}-W_{t^{*} t}^{*} W_{t t^{*}}>0$, which follows from Assumption 1.

PROPOSITION 1. Under noncooperative tax setting, an increase in public infrastructure increases the optimal tax in the investing country. 
Proof. See Appendix.

Using the expressions for $W_{t x}, W_{t x^{*}}, W_{t^{*} x^{*}}^{*}$ and $W_{t^{*} x}^{*}$ we can rewrite expression (13b) and the analogous expression $d t^{N} / d x^{*}$ as:

$$
\mathrm{d} t^{* N} / \mathrm{d} x=A(\lambda-\bar{\lambda})
$$

and

$$
\mathrm{d} t^{N} / \mathrm{d} x^{*}=A^{*}\left(\lambda^{*}-\bar{\lambda}^{*}\right)
$$

with $A \equiv-r^{*} B_{x} W_{t t} / \Delta>0, A^{*} \equiv-r B_{x^{*}}^{*} W_{t^{*} t^{*}}^{*} / \Delta>$ $0, \bar{\lambda} \equiv\left(W_{t^{*}}^{*} R\right) /\left(W_{t t} r^{*}\right)$, and $\bar{\lambda}^{*}=\left(W_{t t^{*}} R^{*}\right) /$ $\left(W_{t^{*} t^{*}}^{*} r\right)$. This gives us the following result.

PROPOSITION 2. Under noncooperative tax setting, (a) an increase in public infrastructure in Home increases (decreases) the optimal tax in the Foreign country if $\lambda>\bar{\lambda}(\lambda<\bar{\lambda}) ;(b)$ an increase in public infrastructure in Foreign increases (decreases) the optimal tax in Home if $\lambda^{*}>\bar{\lambda}^{*}\left(\lambda^{*}<\bar{\lambda}^{*}\right)$.

The critical externality levels, $\bar{\lambda}$ and $\bar{\lambda}^{*}$, above which an increase in public infrastructure raises the rival location's corporate tax, are negative when taxes are strategic complements but positive when taxes are strategic substitutes. To understand this intuitively, it is helpful to first examine the special case in which Foreign's tax reaction function does not shift when Home infrastructure changes (i.e., in the case that $B^{*}$ is independent of $x$ ). Then, since an increase in Home infrastructure shifts Home's tax reaction function to the right, it clearly raises the Foreign tax if the Foreign reaction function is upward sloping $\left(W_{t^{*}+}^{*}>0\right)$, but reduces the tax when the Foreign reaction function slopes down $\left(W_{t^{*} t}^{*}<0\right)$. Now, allow for the Foreign reaction function to shift when Home infrastructure increases (i.e., in the case that $B^{*}$ directly depends on $x$ ). When the cross-border externality is positive, the Foreign reaction function shifts out, working toward a higher Foreign tax. But, if the externality is negative, the Foreign reaction function shifts in, which works toward a reduction in the tax. So, for an increase in Home infrastructure not to increase the Foreign tax when the Foreign reaction function is upward sloping (i.e., $W_{t^{*} t}^{*}>0$ ) requires that the externality be sufficiently negative; for it not to lead to a decrease in the Foreign tax when the Foreign reaction function slopes down (i.e., $W_{t^{*} t}^{*}<0$ ) requires that the externality be positive enough.

In Section II, we discussed the fact that FDI and public infrastructure can provide many benefits in addition to tax revenue. We used $G\left(t, t^{*}\right.$, $\left.x, x^{*}\right)$ and $G^{*}\left(t, t^{*}, x, x^{*}\right)$ to capture these benefits. Let us now briefly consider what difference the inclusion of $G$ and $G^{*}$ in the welfare functions makes.

First, with Home welfare written in its enhanced form as $W=t B+G-\Omega$, the firstorder condition for the Home tax is now $t B_{t}+B+G_{t}=0$. Hence, the optimal tax can be written as $t=-\left(B / B_{t}\right)-\left(G_{t} / B_{t}\right)$. We saw in Section II that, when an increase in FDI has an overall positive effect on the domestic economy, $G_{t}$ must be negative. A negative $G_{t}$ works toward a lower tax. The intuition is straightforward. The government has additional reasons to attract FDI and so has a stronger incentive to cut the corporate tax rate. However, if there is a strong enough crowding out effect of FDI on domestic firms and the activity of these firms matters enough to the government, $G_{t}$ can change sign and become positive. A positive $G_{t}$ works toward a higher corporate tax.

Second, there is a more subtle effect on the strategic incentive to invest in public infrastructure. When additional benefits of FDI and public infrastructure are taken into account, investment in infrastructure could in some cases shift a country's tax reaction function inward rather than outward. This would, however, only be the case if $G_{t x}$ is sufficiently negative such that $W_{t x}=B_{x}+t B_{t x}+G_{t x}<0$ (Assumption 2 ensures $\left.B_{x}+t B_{t x}>0\right)$. So, when would $G_{t x}$ be negative? Intuitively, this could occur when public infrastructure increases the nontax benefit to the country of FDI. To see this, assume that $G_{t}$ is negative. If infrastructure makes FDI even more useful to the country, then $x$ tends to make $G_{t}$ even more negative $\left(G_{t x}<0\right)$. So, for instance, a country with a more developed education system may have a greater capacity to absorb and make productive use of spillovers from foreign multinationals. Such an "absorptive capacity" effect thus works toward $G_{t x}$ being negative. If $G_{t x}$ is sufficiently negative, then $W_{t x}<0$ and $\psi_{x}<0$, thus working to reverse the strategic incentive to invest in public infrastructure. For instance, if taxes are strategic complements, an increase in Home's infrastructure works toward a reduction in both taxes rather than an increase. 
In the remainder of the article, we return to the case in which $G=G^{*}=0$.

Stage 1: Investment in Public Infrastructure under Tax Competition. We now determine the countries' optimal investment in infrastructure. For ease of exposition we will focus on H's choice. F's choice of investment is completely analogous. The first-order condition for Home welfare maximization is given by (6) with $W_{t}=0$ from the second stage. The first term in expression (6), the direct effect of $x$ on Home welfare, is equal to $W_{x}=t B_{x}-\Omega^{\prime}$. The sign of the strategic term, the last term in expression (6), determines whether the Home government will, in order to manipulate the tax rates set in the rival host country, over- or underinvest relative to the hypothetical nonstrategic benchmark. Recall that this benchmark was earlier defined in Section III as the case in which governments choose public infrastructure and tax rates at the same time, implying that first-order conditions for $x$ and $x^{*}$ reduce to $W_{x}=0$ and $W_{x^{*}}^{*}=0$.

PROPOSITION 3. Under noncooperative tax setting, the Home government will (a) strategically overinvest in public infrastructure relative to the nonstrategic benchmark if $d t^{*} / d x>0 ;(b)$ strategically underinvest in public infrastructure relative to the nonstrategic benchmark if $d \mathrm{t}^{*} / d x<0$.

Proof. To determine which of these cases will occur, we need to examine the strategic term in detail. The term can be decomposed into $W_{t^{*}}$ and $\mathrm{d} t^{*} / \mathrm{d} x$. We have $W_{t^{*}}=t B_{t^{*}}>0$, implying that the Foreign tax rate is "friendly," which means that a rise in Foreign's tax rate increases Home welfare. The sign of the strategic term therefore depends on the sign of $\mathrm{d} t^{*} / \mathrm{d} x$.

\section{B. Tax Cooperation}

In this subsection, we restrict attention to symmetric countries.

ASSUMPTION 5. The countries are identical: they have symmetric tax base functions and identical public infrastructure cost functions.

This assumption will facilitate a comparison with the first best, which we will discuss in the next section. The first-order condition for the jointly optimal tax is given by expression (9), with $W_{\tau}=W_{\tau}^{*}$ in a symmetric equilibrium and so
$2 W_{\tau}=0$ (from expression (9)), implying $W_{\tau}=0$. To compare the harmonized and nonharmonized taxes, note that $W_{\tau}=0$ can be written as $W_{t}+$ $W_{t^{*}}=0$. As $W_{t^{*}}>0$, this implies $W_{t}<0$, meaning that, at given (symmetric) public infrastructure investment levels, the cooperative taxes are higher than those under noncooperation.

In stage 1, the Home country chooses its public infrastructural investment noncooperatively, for which the first-order condition is given by expression (11). As the equilibrium in public infrastructure is symmetric, $W_{\tau}+W_{\tau}^{*}=2 W_{\tau}=0$. In turn, this implies $W_{x}=0$ (from expression (11)) and, as discussed in the previous section, this means that investment is set according to the nonstrategic simultaneous-move benchmark.

PROPOSITION 4. When countries are symmetric, tax cooperation eliminates strategic investment in public infrastructure.

Thus, our findings in the LQ-case for tax cooperation continue to hold with general functional forms.

\section{TAX COMPETITION VERSUS TAX COOPERATION: A WELFARE COMPARISON}

In this section, we compare welfare levels under tax competition and tax cooperation. It is a priori not certain that cooperative tax setting alone will yield higher welfare levels than tax competition since, even under tax cooperation, countries set their infrastructure independently. First, we show that tax cooperation typically does not yield the "first-best" outcome. Second, we determine the conditions under which tax competition actually yields an outcome that is welfare superior to the outcome under tax cooperation.

\section{A. The First Best}

The first-best outcome is reached when a social planner, maximizing joint welfare of Home and Foreign, decides on the tax rate and each country's investment in public infrastructure. This outcome is replicated by the countries jointly setting both the tax rate and public infrastructure levels to maximize their joint welfare, that is, when the countries cooperate on public infrastructure and taxes. Assuming that the optimization problem has a unique interior solution, the first-order condition for the first-best tax is given by expression (9), whereas the optimal choice of infrastructure is given by: 


$$
W_{x}+W_{x}^{*}=0
$$

where $W_{x}=\tau B_{x}-\Omega^{\prime}$ and $W_{x}^{*}=\tau B_{x}^{*}$. The following proposition does not rely on special functional forms.

PROPOSITION 5. With symmetric countries the cooperative tax outcome coincides with the first-best joint optimum only when $\lambda=0$.

Proof. At $\lambda=0, W_{x}^{*}=0$, which implies that expression (15) is reduced to $W_{x}=0$. In addition, the first-order condition for the first-best tax is given by expression (9). Hence, at $\lambda=0$, both first-order conditions for the first best are identical to those for the case with tax cooperation alone.

At the first best, unlike at the cooperative harmonized tax equilibrium, each country's public infrastructural investment is chosen taking full account of the external effect on the other country's welfare. Hence, tax cooperation alone will not yield the first-best outcome when public infrastructure investment generates cross-border externalities. To attain the first best when there are cross-border positive or negative externalities would require the countries to not just cooperate on taxes but to cooperate on public infrastructure as well. ${ }^{27}$

\section{B. Tax Competition Versus Tax Cooperation}

We now show that the tax cooperation may even yield a lower welfare level than tax competition when one country's public infrastructure investment generates externalities for the other host country. Since a welfare comparison between tax cooperation and tax competition requires specific functional forms, we use the LQ version of our model.

In Figures $2 \mathrm{~A}-\mathrm{C}$, we again depict the firstorder conditions for infrastructure and taxes in symmetric $(x, t)$-space; these are now not only shown for tax competition $\left(x^{N}(t)\right.$ and $\left.t^{N}(x)\right)$ and for tax cooperation $\left(x^{C}(\tau)\right.$ and $\left.\tau^{C}(x)\right)$, but also for the first best $\left(x^{O}(\tau)\right.$ and $\left.\tau^{O}(x)\right)$, where the

27. There are examples of cross-border cooperation on particular public infrastructural projects of the type that generate positive international spillovers. Examples include the United Kingdom, Belgium, and France cooperating on the Eurostar train link, and Germany and Denmark cooperating on the Fehmarnbelt tunnel to link the two countries. Examples of infrastructural cooperation to limit cross border business stealing are less evident. first-best outcome is represented by point $\mathrm{O}$. In Figure $2 \mathrm{~A}$, there is no externality from public infrastructure investment $(\lambda=0)$. In that case, as shown by Proposition 5, tax cooperation actually yields the first-best outcome and hence the first-best welfare level, whereas tax competition clearly attains a lower welfare level (represented by the fact that it lies on the $W^{N}$-isowelfare contour, with $\left.W^{N}<W^{O}\right)$. When there is an externality, positive or negative, welfare under tax cooperation always falls below the first-best welfare level. Nevertheless, for positive externalities $(\lambda>0)$, tax cooperation always yields a higher welfare level than tax competition, which is illustrated in Figure 2B $\left(W^{C}>W^{N}\right)$. However, this is not always the case when the externality is negative $(\lambda<0)$. Why is this so? With tax cooperation equilibrium tax rates are higher than with tax competition. This implies that levels of public infrastructure investment are higher with tax cooperation than with competition. However, with each country investing in public infrastructure that is harmful to the other host country, the externality will lower welfare in each country. Furthermore, when investment in public infrastructure is relatively effective (i.e., when $\eta$, defined earlier as $\gamma^{2} / \omega$, is high), investment under tax cooperation will be a lot higher than with tax competition, thereby magnifying the negative welfare effect of public infrastructure investment on each country.

In the LQ case under tax competition, the first-order condition for welfare maximization $W_{t}=B+t B_{t}=0$ implies $B=$ $-t B_{t}=\beta t^{N}$. Also, since $W_{x}=t \gamma-\omega x$, $W_{t^{*}}=t \beta \epsilon$, and $d t^{*} / d x=(2 \lambda+\epsilon) \gamma /\left[\beta\left(4-\epsilon^{2}\right)\right]$ in expression (6), we can write $x^{N}=$ $(\eta / \gamma)\left[1+2 \epsilon\left((\lambda-\bar{\lambda}) /\left(4-\epsilon^{2}\right)\right)\right] t^{N}$. Hence, each region's welfare level under tax competition is given by:

$$
\begin{aligned}
& W^{N}=\beta\left[1-\frac{\eta}{2 \beta}\left[1+2 \epsilon \frac{(\lambda-\bar{\lambda})}{4-\epsilon^{2}}\right)^{2}\right]\left(t^{N}\right)^{2}=W^{* N} \\
& \text { with } t^{N}=t^{* N}=\frac{\alpha}{\beta(2-\epsilon)-\eta(1+\lambda)\left(1+2 \epsilon \frac{\lambda-\bar{\lambda}}{4-\epsilon^{2}}\right)} .
\end{aligned}
$$

With tax cooperation and symmetric countries, expression (9) implies $2 W_{\tau}=0$, hence $B=-\tau B_{\tau}=\beta(1-\epsilon) \tau$. Furthermore, $W_{x}=\tau \gamma-\omega x$ and $\mathrm{d} \tau / \mathrm{d} x=(1+\lambda) \gamma /[4 \beta(1-\epsilon)]$ from expression (10). Hence, welfare in each jurisdiction under tax cooperation is equal to: 


\section{FIGURE 2}

Tax Rates and Public Infrastructure Investment Levels: Tax Competition versus Cooperation-The Symmetric Linear-Quadratic Case. (A) $\lambda=0$, (B) $\lambda>0$, and (C) $\lambda<\bar{\lambda}$

(A) $\lambda=0$

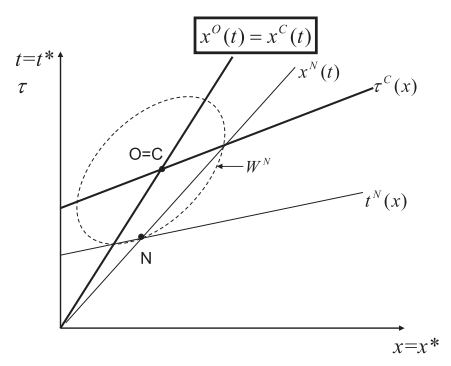

(B) $\lambda>0$

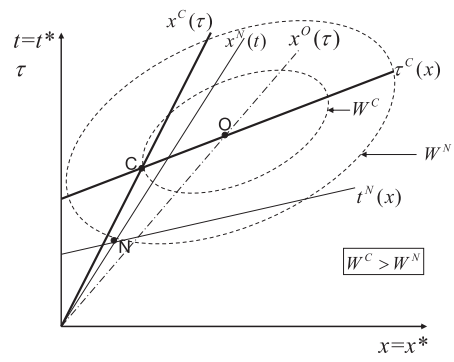

(C) $\lambda<\bar{\lambda}$

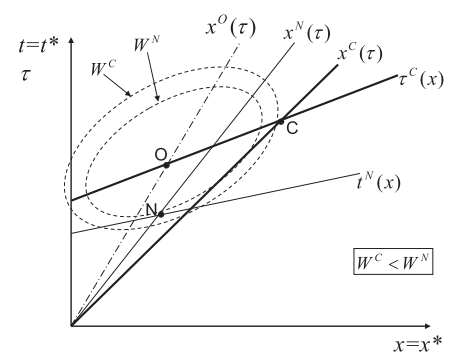

$$
W^{C}=\beta[(1-\epsilon)-(\eta / 2 \beta)] \tau^{2}=W^{* C}
$$

with $\tau=\alpha /[2 \beta(1-\epsilon)-\eta(1+\lambda)]$.

Even in the LQ case, the welfare expressions (expressions (16) and (17)) are not easy to compare. It is helpful to illustrate the welfare comparison diagrammatically. We use two figures to do this. Figure 3A depicts welfare under tax competition and tax cooperation (as well as in the first best) as functions of $\lambda$. In the diagram, when $\lambda$ is sufficiently negative, welfare under tax competition is higher than under tax cooperation. Obviously, this diagram is drawn for specific parameter values. While it is true that when externalities from public infrastructure are positive, tax cooperation always yields higher welfare than tax competition, tax cooperation does not necessarily give lower welfare than tax competition when externalities are negative. In fact, it is also necessary that, at the same time as the externality being negative, the relative effectiveness of public infrastructure $(\eta)$ is high. Figure $3 \mathrm{~B}$ demonstrates this by showing welfare under the three regimes (tax competition, tax cooperation, and the first best) as a function of $\eta$; note that in this figure $\lambda<0$ ). At the threshold $\widetilde{\eta}$, welfare under tax competition and cooperation are equal. For low levels of $\eta(\eta<\widetilde{\eta})$, tax cooperation generates higher welfare than tax competition. However, for $\eta$-levels beyond $\widetilde{\eta}(\eta>\widetilde{\eta})$, the welfare level attained under tax competition is higher than under tax cooperation.

PROPOSITION 6. In the LQ-case, there exists a critical $\eta$-threshold, $\widetilde{\eta}(\lambda)$, with $(i) W^{C}(\widetilde{\eta})=$ $W^{N}(\widetilde{\eta})$ and $(i i) \mathrm{d} \tilde{\eta} / \mathrm{d} \lambda>0$.
Proof. See Appendix.

\section{EXTENSIONS}

This section briefly discusses some extensions of the model. ${ }^{28}$ In the respective subsections, we address what happens if the countries that are contemplating tax harmonization were asymmetric, we discuss the outcomes of the game if taxes were chosen prior to infrastructure, we extend our results to a setup with more than two jurisdictions, and finally discuss what would happen under an alternative form of tax harmonization.

\section{A. Asymmetric Countries}

So far, we assumed the countries involved are symmetric. In this subsection, we discuss the effects of tax cooperation when countries are asymmetric. $^{29}$

We introduce country asymmetry in the most straightforward way, that is, by assuming that one of the countries, Home, has, ceteris paribus, a higher multinational tax base than Foreign, which is captured in the LQ version of the model by introducing a parameter $\alpha^{*}$ in the tax base function for Foreign, with $\alpha^{*}<\alpha$. This could be because Home has an underlying advantage

28. The formal analysis for these extensions is available from the authors on request.

29. The existing literature has identified country asymmetry as a potential reason why tax harmonization may reduce welfare. Our model shows that, even when countries are symmetric, tax cooperation may lower welfare. Here, we show that this result also holds when countries are asymmetric. This is particularly true for the less attractive country. 


\section{FIGURE 3}

Welfare under Tax Cooperation and Tax Competition-The Symmetric Case. (A) Welfare and the Externality, (B) Welfare and the Effectiveness of Public Infrastructure Investment

(A) Welfare and the externality

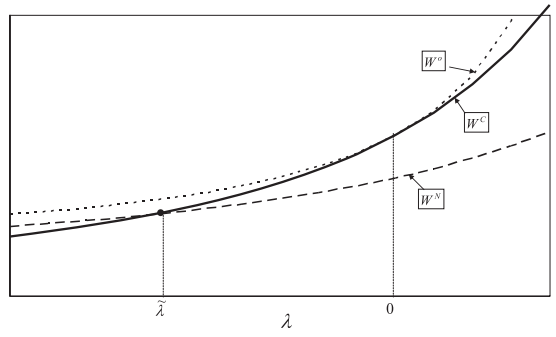

in attracting FDI. Henceforth, we will refer to the "naturally more attractive" country as Home for short. In the equilibrium with tax competition, Home will now charge a higher tax rate than Foreign, while also investing more in public infrastructure. When the countries cooperate and set a common tax rate, $\tau$, the common (harmonized) tax rate is chosen to maximize the sum of Home and Foreign welfare, $W+W^{*}$. Welfare is always higher in Home, that is, the country that is "naturally more attractive" for FDI; so, $W^{N}>W^{* N}$ and $W^{C}>W^{*} C$. As in the case with symmetric countries, whether a country gains or loses from tax cooperation depends on the relative effectiveness of public infrastructure investment and on the level of the externality. When the externality parameter is high, both countries gain from tax cooperation and will agree to harmonize taxes. However, when the externality is sufficiently negative, tax cooperation harms both countries and there will be no incentive to set taxes cooperatively. For intermediate externality levels, the "naturally more attractive" country (Home) prefers tax cooperation to tax competition, while the opposite is true for the "naturally less attractive" country. This result suggests that a peripheral, less developed country may be less favorably disposed toward tax harmonization than a core, highly developed country that is more naturally attractive to FDI. In that case, countries may wish to bargain over sidepayments to sustain tax cooperation.

\section{B. Reversing the Move Order: Taxes before Infrastructure}

As we explained earlier, infrastructure is chosen before taxes in our model because it is seen
(B) Welfare and the effectiveness of public infrastructure investment

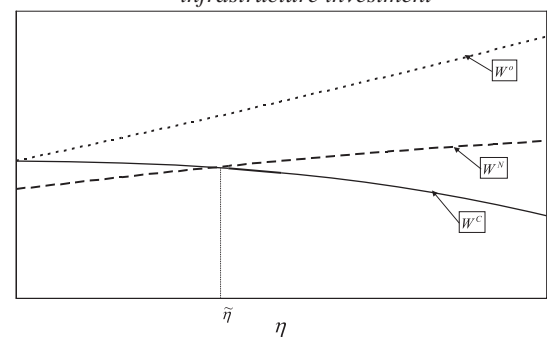

as having more commitment value than taxes: it involves a long-run decision and is to a large extent irreversible. However, it is worth briefly discussing what would happen in the alternative case in which the sequence of decisions regarding infrastructure and taxes is reversed.

If the sequence of decisions were reversed, infrastructure would be chosen in stage 2, taking the taxes as given. Clearly, there would no longer be scope to use infrastructure to strategically influence the tax rates of the other jurisdiction. Home's stage 2 first-order condition for infrastructure would be given by $W_{x}=0$. In stage 1 , taxes would be chosen taking account of any effects that they would have on the future infrastructural choice. In general, governments could use taxes to strategically manipulate their rivals' infrastructure. This effect cannot be definitely signed in general, but it is zero in the linear case. So, in the linear case, the noncooperative outcome differs from that in our model in which infrastructure is chosen before tax rates, because of the absence of a strategic motive for infrastructure, whereas the outcome under cooperation is identical to that in our model.

\section{Many Jurisdictions}

So far, we have restricted attention to the case of two jurisdictions. With $n$ countries, Equation (3a) and (3b) can be replaced by:

$$
B_{i}=\alpha-\beta\left(t_{i}-\epsilon T_{-i}\right)+\gamma\left(x_{i}+\lambda X_{-i}\right)
$$

where $B_{i}$ is a typical country $i$ 's tax base, $t_{i}$ is its tax rate, and $x_{i}$ is its infrastructure. Here, we write $T_{-i}=\Sigma_{j \neq i} t_{j}$ and $X_{-i}=\Sigma_{j \neq i} x_{j}$. The welfare of country $i$ can be written as: $W_{i}=t_{i} B_{i}-(\omega / 2) x_{i}^{2}$. 
From this we can derive country $i$ 's secondstage noncooperative equilibrium tax and the effect of a country's investment in public infrastructure on another country's corporate tax rate $\left(\mathrm{d} t_{j}^{N} / \mathrm{d} x_{i}\right)$ :

$$
\frac{\mathrm{d} t_{j}^{N}}{\mathrm{~d} x_{i}}=\gamma \frac{2 \lambda+\epsilon}{\beta(2+\epsilon)(2-(n-1) \epsilon)} .
$$

Expression (19) shows that, as in the two country case, the sign of the strategic term continues to depend on whether $\lambda$ is greater or smaller than the critical value, $-\epsilon / 2$. Although it is the case that the strategic effect of infrastructure is stronger when each country is playing against more rival jurisdictions, the addition of more countries does not qualitatively affect this or the other results.

\section{Harmonized Minimum Tax Rates}

We now consider an alternative form of tax harmonization. Suppose taxes are constrained not to fall below a minimum tax. Given this tax floor, countries play a noncooperative two-stage game, setting infrastructure in stage 1 and taxes in stage 2. When the minimum tax rate is higher than $t^{N}$, the equilibrium tax rate in each region is $\tau^{M}$. There is then no longer any need to choose public infrastructure investment levels strategically as the legally imposed minimum tax rate effectively pushes the tax rates beyond the level that would prevail when governments are unconstrained in choosing taxes. This implies that one can expect a minimum tax, if effective, to increase investment in public infrastructure when the latter generates a sufficiently negative crossborder externality $(\lambda<\bar{\lambda}$, in which case there is an incentive to underinvest in public infrastructure in the absence of a minimum tax). When public infrastructure generates a cross-border externality that is above a critical threshold level (i.e., $\lambda>\bar{\lambda}$ ), the minimum tax rate eliminates the strategic incentive to overinvest in public infrastructure, which works toward a lower level of infrastructure. However, the tax floor now ensures a higher tax rate and since the public infrastructure investment level is itself increasing in the tax rate, there is a countervailing effect on the infrastructure level that works toward increasing it. When the minimum tax is sufficiently high, this second effect dominates and the infrastructure is higher than in the noncooperative case.

\section{CONCLUSION}

A country's ability to attract inward FDI depends, among other things, on corporate tax rates and on the level and quality of local public infrastructure. Since a potential host country can attract more FDI by increasing its investment in public infrastructure, the multinational firm component of its tax base thus depends in part on the level of local public infrastructure. Moreover, public infrastructural investment in one country can also affect the attractiveness and hence the multinational tax base of a competing host country, and may do so either positively or negatively.

To study these issues, we have constructed a two-country model of corporate tax competition for inward FDI, in which governments also invest in public infrastructure. When the externality generated by one country's investment in public infrastructure is above a critical threshold level, governments strategically increase their investment in infrastructure in order to raise the rival host country's corporate tax rate. This softens tax competition and therefore benefits the investing host country indirectly. However, if the externality is below that critical threshold (for instance as a result of a strong business stealing effect), then the strategic effect of public infrastructure is negative and the investing country has an incentive to lower its public infrastructure investment.

The external effect of public infrastructure on the other country also affects the gains from tax harmonization. Although tax cooperation can raise the welfare of countries, we have found that - even when countries are symmetric - this is not always the case. In fact, when infrastructure is sufficiently cost effective in enhancing a country's attractiveness and hence in raising its own tax base while generating a sufficiently large negative cross-border externality, then tax cooperation, without infrastructure coordination, actually reduces welfare. The reason for this lies in the fact that, although resulting in higher equilibrium taxes and hence avoiding a race to the bottom in tax rates, tax cooperation also leads to higher investment in public infrastructure. When countries coordinate taxes but not infrastructure, they ignore the business stealing negative externality that their infrastructure imposes on other countries and they engage in excessive (mutually damaging) investment. When this effect is strong enough, tax cooperation results in lower welfare levels than tax competition. 
Our results are cautionary as they imply that policymakers may inadvertently make matters worse by signing up to tax harmonization programs without consideration of regional public infrastructure investment schemes. Specifically, it provides policymakers of competing jurisdictions who consider tax harmonization with a rule of thumb. If tax cooperation, which is the form of tax harmonization that leads to the highest welfare at given infrastructure levels when countries are very similar, actually reduces welfare below the level attained with tax competition, then alternative forms of tax harmonization cannot be expected to raise welfare levels either. We found that, when rival host jurisdictions experience very negative cross-border spillovers from each other's public infrastructure investment projects, policymakers should be most wary of any form of tax harmonization. By contrast, if cross-border spillovers from public infrastructure investment are positive, or negative but small, our model suggests that in those circumstances tax harmonization is more likely to bear fruit.

\section{APPENDIX}

Proof of Proposition 1. Under noncooperative tax setting, an increase in public investment increases the optimal tax in the investing country. Here, we will examine the case of the Home country.

From $\frac{\mathrm{d} t^{N}}{\mathrm{~d} x}=\frac{W_{t^{*} x}^{*} W_{t t^{*}}-W_{t^{*} t^{*}}^{*} W_{t x}}{\Delta}$, we know that the sign depends on that of the numerator since $\Delta>0$ from Assumption 1. To determine the sign of the numerator, note that the derivative $W_{t^{*} t^{*}}^{*}$ is negative from the second-order condition for the foreign country and $W_{t x}$ is positive from Assumption 2. So, it is the case that $-W_{t^{*} t^{*}}^{*} W_{t x}>0$. This leads us to consider 4 cases:

Case (1): $W_{t t^{*}}>0$ (taxes are strategic complements) and $W_{t^{*} x}^{*} \geq 0$ (public infrastructure generates a non-negative cross-border externality).

Case (2): $W_{t t^{*}}<0$ (taxes are strategic substitutes) and $W_{t^{*} x}^{*} \leq 0$ (public infrastructure generates a nonpositive cross-border externality).

Case (3): $W_{t t^{*}}>0$ (taxes are strategic complements) and $W_{t^{*} x}^{*} \leq 0$ (public infrastructure generates a nonpositive crossborder externality).

Case (4): $W_{t t^{*}}<0$ (taxes are strategic substitutes) and $W_{t^{*} x}^{*} \geq 0$ (public infrastructure generates a nonnegative cross-border externality).

It is clear that $\mathrm{d} t^{N} / \mathrm{d} x$ is guaranteed to be positive in cases (1) and (2) above as then $W_{t^{*} x}^{*} W_{t t^{*}} \geq 0$, which reinforces $-W_{t^{*} t^{*}}^{*} W_{t x}>0$. It remains to be shown that $\mathrm{d} t^{N} / \mathrm{d} x$ is also positive in cases (3) and (4). In case (3), Assumption 3, which states $\left|\psi_{x}\right| \geq\left|\psi_{x}^{*}\right|$, implies $-W_{t x} / W_{t t} \geq W_{t^{*} x}^{*} / W_{t^{*} t^{*}}^{*}>0$ and so $W_{t x} \geq-W_{t t}\left(W_{t^{*} x}^{*} / W_{t^{*} t^{*}}^{*}\right)>0$. Hence, the numerator $-W_{t^{*} t^{*}}^{*} W_{t x}+W_{t^{*} x}^{*} W_{t t^{*}}$ is $^{*}$ at least as large as $W_{t t}\left(W_{t^{*} x}^{*} / W_{t^{*} t^{*}}^{*}\right) W_{t^{*} t^{*}}^{*}+W_{t^{*} x}^{*} W_{t t^{*}}=W_{t^{*} x}^{*}\left(W_{t t}+W_{t t^{*}}\right)>0$ since the term in brackets is negative from Assumption 1. Hence, we conclude $\mathrm{d} t^{N} / \mathrm{d} x=\left(W_{t^{*} x}^{*} W_{t t^{*}}-W_{t^{*} t^{*}}^{*} W_{t x}\right) / \Delta>$ 0 . Next, consider case (4). Now, Assumption 3, which states $\left|\psi_{x}\right| \geq\left|\psi_{x}^{*}\right|$, implies $-W_{t x} / W_{t t} \geq-W_{t^{*} x}^{*} / W_{t^{*} t^{*}}^{*}>0$ and so $W_{t x} \geq W_{t t}\left(W_{t^{*} x}^{*} / W_{t^{*} t^{*}}^{*}\right)>0$. Hence, the numerator $-W_{t^{*} t^{*}}^{*} W_{t x}+W_{t^{*} x}^{*} W_{t t^{*}}$ is at least as large as $-W_{t^{*} x}^{*}\left(W_{t t}-W_{t t^{*}}\right)>0$ since the term in brackets is negative from Assumption 1.

Analogous derivations can be used to show $\mathrm{d} t^{* N} / \mathrm{d} x^{*}>0$.

Proof of Proposition 6. The threshold $\tilde{\eta}$ is defined by $W^{N}(\widetilde{\eta})=W^{C}(\widetilde{\eta})$. Using expressions (16) and (17), we obtain the following quadratic function in $\tilde{\eta}$ :

$$
V \widetilde{\eta}^{2}+Z \widetilde{\eta}+E=0
$$

with $V \equiv-2(1+\lambda)\left[(1-\epsilon)(1-\lambda) S^{2}-(2-\epsilon) S+(1+\lambda)\right]$, $Z \equiv 4(1-\epsilon)^{2} S^{2}+4(1-\epsilon)(1+\lambda)[2-(2-\epsilon) S]-(2-\epsilon)^{2}$,

$E \equiv 2(1-\epsilon) \epsilon^{2}$, and $S \equiv 1+2 \epsilon(\lambda-\bar{\lambda}) /\left(4-\epsilon^{2}\right)$. Solving expression ((A1)) for $\tilde{\eta}$, selecting the relevant root, yields $\tilde{\eta}=-\left(Z+\sqrt{Z^{2}-4 V E}\right) / 2 V>0$.

\section{REFERENCES}

Aitkin, B., and A. Harrison. "Do Domestic Firms Benefit from Direct Foreign Investment? Evidence from Venezuela." American Economic Review, 89, 1999, 605-18.

Alesina, A., and R. Wacziarg. "Openness, Country Size and Government." Journal of Public Economics, 69, 1998, $305-21$.

Baskaran, T., and M. Lopes da Fonseca. "The Economics and Empirics of Tax Competition." Centre for European Governance and Economic Development Research, Discussion Paper No. 163, 2013.

Bayindir-Upmann, T. "Two Games of Interjurisdictional Competition When Local Governments Provide Industrial Public Goods." International Tax and Public Finance, 5, 1998, 471-87.

Bénassy-Quéré, A., N. Gobalraja, and A. Trannoy. "Tax and Public Input Competition." Economic Policy, 22, 2007, 385-430.

Boarnet, M. G. "Spillovers and the Locational Effects of Public Infrastructure.” Journal of Regional Science, 38, 1998, 381-400.

Bouwmeester, M., and L. Scholtens. "Cross-Border Investment Expenditure Spillovers in European Gas Infrastructure." Energy Policy, 107, 2017, 371-80.

Brakman S., H. Garretsen, and C. van Marrewijk. "Locational Competition and Agglomeration: The Role of Public Spending." CCSO Working Paper No. 200209, 2002.

Brander, J. "Strategic Trade Policy," in Handbook of International Economics, Vol. III, edited by G. Grossman and K. Rogoff. Amsterdam, The Netherlands: NorthHolland, 1995, 1395-455.

Bucovetsky, S. "Public Input Competition." Journal of Public Economics, 89, 2005, 1763-87.

Chen, Y.-F., H. Görg, D. Görlich, H. Molana, C. Montagna, and Y. Temouri. "Globalisation and the Future of the Welfare State, IZA.” Policy Paper No. 81, 2014.

Cohen, J., and C. Morrison Paul. "Airport Infrastructure Spillovers in a Network System." Journal of Urban Economics, 54, 2003, 459-73.

. "Public Infrastructure Investment, Inter-State Spatial Spillovers, and Manufacturing Costs." Review of Economics and Statistics, 86, 2004, 551-60.

Cremer, H., V. Forgeaud, M. Leite-Monteiro, M. Marchand, and P. Pestieau. "Mobility and Redistribution: A Survey." Public Finance, 51, 1997, 325-52.

Dembour, C., and X. Wauthy. "Investment in Public Infrastructure with Spillovers and Tax Competition between Contiguous Regions." Regional Science and Urban Economics, 39, 2009, 679-87. 
Devereux, M., B. Lockwood, and M. Redoano. "Do Countries Compete over Corporate Tax Rates?" Journal of Public Economics, 92, 2008, 1210-35.

Egger, H., and J. Falkinger. "The Role of Public Infrastructure and Subsidies for Form Location and International Outsourcing." European Economic Review, 50, 2006, 1993-2015.

Fudenberg, D., and J. Tirole. "The Fat-Cat Effect, the PuppyDog Ploy, and the Lean and Hungry Look." American Economic Review, 74, 1984, 361-66.

Gomes, P. and F. Pouget. "Corporate Tax Competition and the Decline of Public Investment, European Central Bank." Working Paper Series No. 928, 2008.

Görg, H., H. Molana, and C. Montagna. "Foreign Direct Investment, Tax Competition and Social Expenditure." International Review of Economics and Finance, 18, 2009, 31-37.

Hauptmeier, S., F. Mittermaier, and J. Rincke. "Fiscal Competition over Taxes and Public Inputs." Regional Science and Urban Economics, 42, 2012, 407-19.

Hindriks, J., S. Peralta, and S. Weber. "Competing in Taxes and Investment under Fiscal Equalization." Journal of Public Economics, 92, 2008, 2392-402.

Jude, C. "Does FDI Crowd Out Domestic Investment in Transition Countries?" HAL Working Paper No. halschs$01252565,2015$.

Keen, M., and M. Marchand. "Fiscal Competition and the Pattern of Public Spending." Journal of Public Economics, 66, 1997, 33-53.

Kreps, D., and J. Scheinkman. "Quantity Precommitment and Bertrand Competition Yield Cournot Outcomes." Bell Journal of Economics, 14, 1983, 326-37.
Martin, P., and C. Rogers. "Industrial Location and Public Infrastructure." Journal of International Economics, 39 , 1995, 335-51.

Moreno, R., and E. López-Bazo. "The Impact of Infrastructure on Regional Economic Growth: Some Results on Its Spillover Effect." Universitat de Barcelona, 2003.

OECD. Foreign Direct Investment for Development. Maximising Benefits, Minimising Costs. Paris: OECD.

Pieretti, P., and S. Zanaj. "On Tax Competition, Public Goods Provision, and Jurisdictions' Size." Journal of International Economics, 84, 2011, 124-30.

Puga, D. "Agglomeration and Crossborder Infrastructure." Luxembourg: European Investment Bank, 2008.

Rodrik, D. "Why Do More Open Economies Have Bigger Governments?" Journal Political Economy, 106, 1998, 997-1032.

Taylor, L. "Infrastructural Competition among Jurisdictions." Journal of Public Economics, 49, 1992, 241-59.

Wilson, J. "A Theory of Interregional Tax Competition." Journal of Urban Economics, 19, 1986, 296-315.

Winner, H. "Fiscal Competition and the Composition of Public Expenditure: An Empirical Study." Contemporary Economics, 6, 2012, 38-54.

Yu, N., M. de Jong, S. Storm, and J. Mi. "Spatial Spillover Effects of Transport Infrastructure: Evidence from Chinese Regions." Journal of Transport Geography, 28, 2012, 56-66.

Zissimos, B., and M. Wooders. "Public Good Differentiation and the Intensity of Tax Competition." Journal of Public Economics, 92, 2008, 1105-21.

Zodrow, G. R. "Capital Mobility and Tax Competition." National Tax Journal, 63, 2010, 865-902. 
Copyright of Economic Inquiry is the property of Wiley-Blackwell and its content may not be copied or emailed to multiple sites or posted to a listserv without the copyright holder's express written permission. However, users may print, download, or email articles for individual use. 